\title{
Nitric Oxide as an Upstream Signal of p38 Mediates Hypoxia/Reoxygenation- Induced Neuronal Death
}

\author{
Ming Chen ${ }^{a}$ Hong-Yu Sun ${ }^{b}$ Shu-Ji Li ${ }^{a}$ Manas Das $^{a}$ Ji-Ming Kong ${ }^{a, c}$ \\ Tian-Ming Gao ${ }^{\text {a }}$ \\ Departments of a Anatomy and Neurobiology, ${ }^{b}$ Physiology, Southern Medical University, Guangzhou, China; \\ 'Department of Human Anatomy and Cell Science, University of Manitoba, Faculty of Medicine, \\ Winnipeg, Man., Canada
}

\section{Key Words}

Hypoxia - Hippocampal neuron - Cell death · Nitric oxide •

Mitogen-activated protein kinase

\begin{abstract}
Nitric oxide (NO) and p38 have been shown to be involved in the ischemia/hypoxia-induced neuronal injury. In this study, we examined the activation patterns of mitogen-activated protein kinases and explored the relationship between $\mathrm{NO}$ and $\mathrm{p} 38$ in a model of hippocampal neuronal death induced by hypoxia/reoxygenation (H/R). p38 activity increased robustly during hypoxia and after reoxygenation, while the increase of c-Jun amino-terminal kinase and extracellular signal-related kinase activities showed mild tendency. Inhibition of p38 with SB203580 or SB202190 rescued neuronal death, whereas inhibition of extracellular signalrelated kinases with PD98059 or c-Jun amino-terminal kinases with SP600125 offered no protection. p38 inhibitors also reduced neuronal death induced by the NO donor S-nitrosoglutathione. L-NAME, a nonspecific NO synthase inhibitor, blocked the p38 activation and rescued H/R-induced neuronal death. These results suggest that $\mathrm{NO}$ is an upstream signal of p38 that mediates the H/R-induced neuronal death.
\end{abstract}

Copyright $\odot 2009$ S. Karger AG, Basel

\section{Introduction}

Hypoxia is an important pathophysiological feature of ischemic diseases such as stroke. Neurons are more vulnerable than other brain cells to reduced oxygen supply, and reoxygenation may further deteriorate the injury. Transient hypoxia/ischemia leads to neuronal death selectively in some brain areas, especially in the hippocampus. Evidence has accumulated that multitude of molecules such as glutamate, free radicals, protein kinases are involved in the hypoxic/ischemic injury. The intracellular signaling pathways, however, are poorly understood $[1,2]$. Nitric oxide (NO) is an intra- and intercellular signaling molecule which plays important roles in regulating calcium influx, synaptic plasticity and cell survival in the adult nervous system in both physiological and pathological settings [3-6]. Upregulation of NO production during ischemia and reperfusion is thought to have either protective or deleterious effects depending on the NO synthase (NOS) isoform from which NO is produced [7]. The main source of $\mathrm{NO}$ in the brain, in absence of inflammation, is neuronal NOS [8]. Although the studies with pharmacological inhibitors and knockout mice implicate a neurotoxic effect of neuronal NOS in ischemic stroke $[9,10]$, the downstream signaling pathways by which NO mediates its neurotoxic effect remain unclear.
Tian-Ming Gao, MD, PhD

Department of Anatomy and Neurobiology

Southern Medical University

Guangzhou 510515 (China)

Tel./Fax +86 206164 8216, E-Mail tgao@fimmu.com 
Mitogen-activated protein kinases (MAPKs) play important roles in cellular response to different stimuli [11]. Among the MAPKs, extracellular signal-related kinases (ERK) are generally responsive to growth factors and have been widely associated with cell survival, whereas c-Jun amino-terminal kinases (JNK) and p38 are activated in response to cytokines or stress and are often implicated in cell death [12]. A growing body of evidence has shown that p38 pathway is activated following cerebral ischemia and contributes to ischemic/hypoxic neuronal death $[13,14]$, but its upstream signaling in mediating this kind of cell death is unknown. We report here that hypoxia/reoxygenation (H/R)-induced death of cultured hippocampal neurons was mediated by NO production and $\mathrm{p} 38$ activation. In addition, NOS inhibitors prevented the rapid activation of $\mathrm{p} 38$, and inhibition of p38 rescued NO-induced neuronal death. Taken together, these observations suggest that $\mathrm{NO}$ is an upstream molecule of p38 in the signaling pathway of hypoxic neuronal death.

\section{Materials and Methods}

\section{Primary Cultures of Hippocampal Neurons}

Primary hippocampal neuronal cultures were prepared from neonatal Sprague-Dawley rats (P1-2) as described previously $[6$, 15]. Hippocampi were dissected and digested by $0.125 \%$ trypsin at $37^{\circ} \mathrm{C}$ for $10 \mathrm{~min}$. Cells were dispersed by gentle agitation and passed through a 200-mesh stainless steel sieve. Cells were plated with a density of $4 \times 10^{5}$ cells $/ \mathrm{cm}^{2}$ on poly-L-lysine-coated culture surface. Culture medium consisted of $90 \%$ DMEM (Gibco) and $10 \%$ fetal bovine serum. Cells were grown at $37^{\circ} \mathrm{C}$ in a humidified atmosphere containing $5 \% \mathrm{CO}_{2}$ and $95 \%$ air. Glial cell growth was controlled by treatment with $10^{-5} \mathrm{M}$ cytosine arabinoside for $48 \mathrm{~h}$ at day 2 in vitro. The percentage of astrocytes is less than $4 \%$ when assessed by GFAP immunocytochemistry, and the percentage of GABAergic interneurons is no more than $5 \%$ when assessed by GAD65 immunocytochemistry. All experiments were performed on the cells cultured for 13-15 days.

\section{Treatment of $H / R$}

Before induction of hypoxia, the culture medium was replaced with DMEM without serum. Neurons were exposed to hypoxia for $4 \mathrm{~h}$ by transferring the culture plates to a humidified incubation chamber thermoregulated at $37^{\circ} \mathrm{C}$ and flushed by a gas mixture consisting of $95 \% \mathrm{~N}_{2} / 5 \% \mathrm{CO}_{2}$. After the hypoxic treatment, the conditioned culture medium was changed back and the cultures were returned to standard normoxic atmosphere for up to $24 \mathrm{~h}$, whereas control cells were constantly maintained under normoxic conditions [16].

\section{Assessment of Neuronal Death}

Neuronal death was assessed by both morphological observation and quantification. Dying neurons appeared as fragmented dendrites and condensed nuclear structures. Quantification was done by a spectrophotometric method using the tetrazolium salt
MTT. Briefly, neurons were incubated for $3 \mathrm{~h}$ at $37^{\circ} \mathrm{C}$ with MTT $(500 \mu \mathrm{g} / \mathrm{ml})$, washed with ice-cold PBS, and lysed in DMSO. Optical density was measured at $570 \mathrm{~nm}$, and data were compared with those obtained from sister control cells.

\section{Western Blot Analysis}

Activation of p38, JNK and ERK was assessed by Western blot analysis. Whole cell extracts were prepared following the manufacturer's protocol (Cell Signaling Technology). At the different time points after the beginning of hypoxia or reoxygenation, cells were washed twice with chilled $\left(4^{\circ} \mathrm{C}\right) \mathrm{PBS}$ and then homogenized on ice with lysis buffer containing $62.5 \mathrm{mM}$ Tris- $\mathrm{HCl}$ (pH 6.8), $2 \%$ SDS, $10 \%$ glycerol, $5 \%$ 2-mercaptoethanol, and $0.01 \%$ bromophenol blue. The proteins were separated by electrophoresis on a $12 \%$ SDS-polyacrylamide gel and electrotransferred to a polyvinylidene difluoride membrane. After blocking with 5\% nonfat milk in Tris-buffered saline containing $0.1 \%$ Tween 20 (TBS/TM), the membranes were incubated overnight at $4^{\circ} \mathrm{C}$ with anti-phosphop38 antibody, anti-phospho-JNK antibody, anti-phospho-ERK antibody, anti-p38 antibody, anti-JNK antibody or anti-ERK antibody (Cell Signaling Technology) diluted 1:1,000 in TBS/TM. The membranes were then washed and incubated with HRP-conjugated secondary antibody $(1: 5,000)$ for $1 \mathrm{~h}$. The immune complex was detected by chemiluminescence (Santa Cruz Biotechnology). The activations of $\mathrm{p} 38$, JNK and ERK were represented by the ratio of phosphorylated kinase bands normalized to the total kinase bands. Actin was used as a loading control.

\section{Statistics}

Data are expressed as the mean \pm SEM for at least three independent experiments. Multiple comparisons were done using one-way ANOVA with LSD post-hoc tests. Changes were identified as significant if the $\mathrm{p}$ value was less than 0.05 .

\section{Results}

\section{Activation of MAPKs Induced by H/R Exposure}

Since the MAPKs are proposed to be involved in the ischemic/hypoxic neuronal death and reoxygenation can further deteriorate the hypoxic injury, we first characterized the activation patterns of $\mathrm{p} 38$, JNK and ERK during hypoxia. Western blot analysis was used to examine the temporal changes in the phosphorylated kinase levels, which represent the activation of the kinases. As shown in figure 1, the activation of p38 was observed as early as 90 min after the beginning of hypoxia, while JNK (54 and $46 \mathrm{kDa}$ ) and ERK (44 and $42 \mathrm{kDa}$ ) showed no significant activation during hypoxia.

We then examined whether p38, JNK and ERK were activated after $H / R$. As seen in figure 2, robust activation of p38 was observed and the phosphorylation of p38 reached the highest level at $0 \mathrm{~h}$, then decreased and recovered at $3 \mathrm{~h}$ after reoxygenation, while JNK and ERK only showed mild tendency of transient increase in H/R-treated cells. 


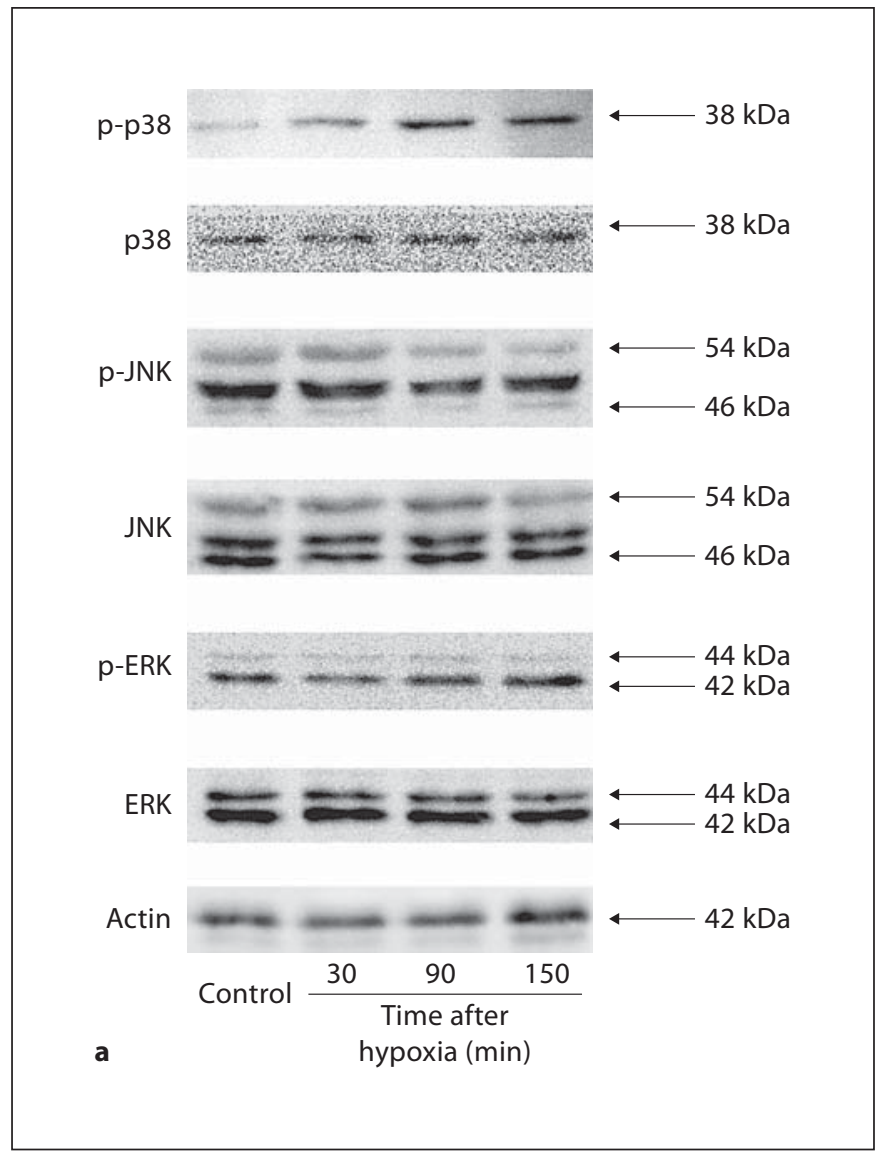

Fig. 1. Activation of p38, JNK and ERK during hypoxia. a Representative Western blots show the expression of phosphorylated and total kinases. b Quantification of the activations of p38, JNK and ERK. Data from three independent experiments ${ }^{*} \mathrm{p}<0.05$ compared with control.

\section{Protection of H/R-Induced Neuronal Death by $p 38$}

Inhibitors

To evaluate the role of MAPKs activation in H/R-induced cell death, the effects of MAPK inhibition were tested. As shown in figure $3, \mathrm{H} / \mathrm{R}$ treatment caused about $30 \%$ neuronal death, as measured by the MTT method. Two specific p38 inhibitors, SB203580 (10 $\mu \mathrm{M})$ or SB202190 $(10 \mu \mathrm{M})$, rescued half of the neuronal death when applied before hypoxia, whereas the inactive analog SB202474 $(10 \mu \mathrm{M})$, ERK inhibitor PD98059 $(10 \mu \mathrm{M})$ or

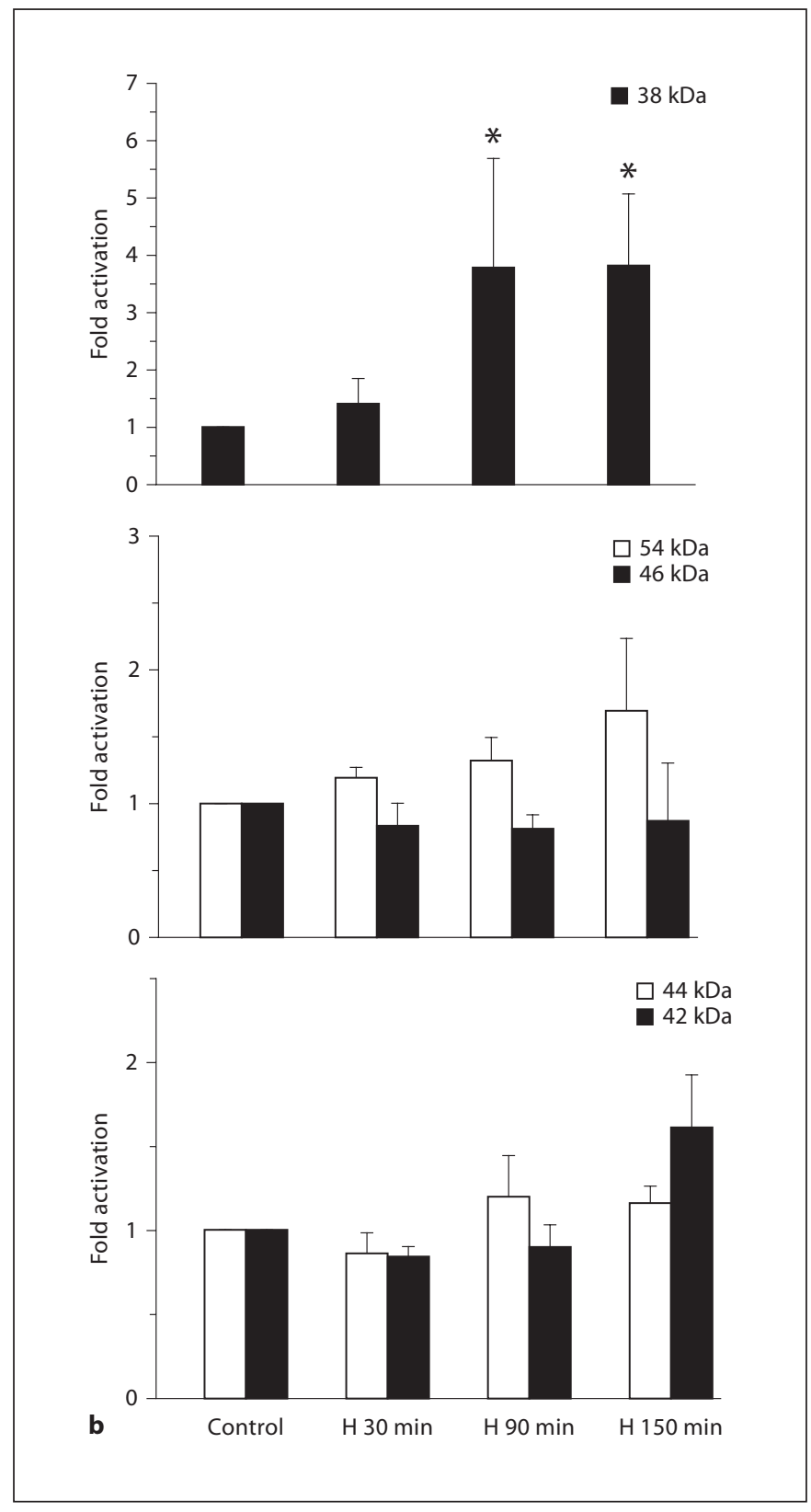

JNK inhibitor SP600125 (10 $\mu \mathrm{M})$ afforded no protection, indicating that p38 acted as an important mediator of H/R-induced neuronal death.

\section{NO Acts Upstream of $p 38$ to Mediate H/R-Induced}

Neuronal Death

To clarify the role of $\mathrm{NO}$ in the H/R-induced neuronal death, a nonspecific NOS inhibitor, L-NAME, was used. L-NAME $(0.1 \mathrm{mM})$ reduced cell death when applied before hypoxia but not after reoxygenation (fig. 4a). Then, 


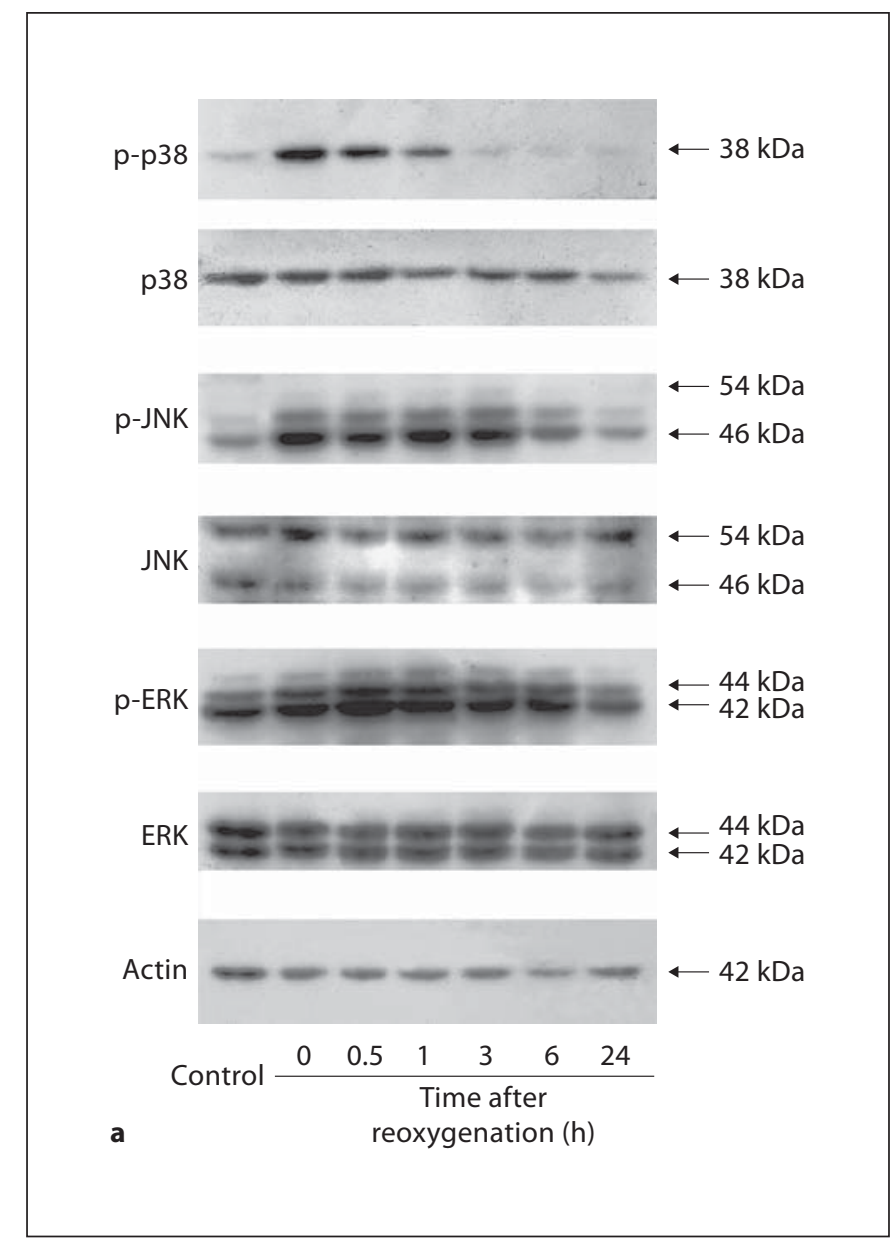

Fig. 2. Activation of $\mathrm{p} 38, \mathrm{JNK}$ and ERK after reoxygenation. a Representative Western blots show the expression of phosphorylated and total kinases. b Quantification of the activations of p38, JNK and ERK. Data from three independent experiments. ${ }^{\#} \mathrm{p}<0.001$ and ${ }^{*} \mathrm{p}<0.05$ compared with control.

we further investigated the relationship between $\mathrm{NO}$ and p38 in the signaling pathway of neuronal death. S-nitrosoglutathione (GSNO), a NO donor that generates $\mathrm{NO}$ through mechanisms independent of NOS, alone induced the death of about $33 \%$ of normal cultured neurons at the concentration of $0.1 \mathrm{mM}$. SB203580 or SB202190 prevented GSNO-induced cell death, while SB202474 showed no
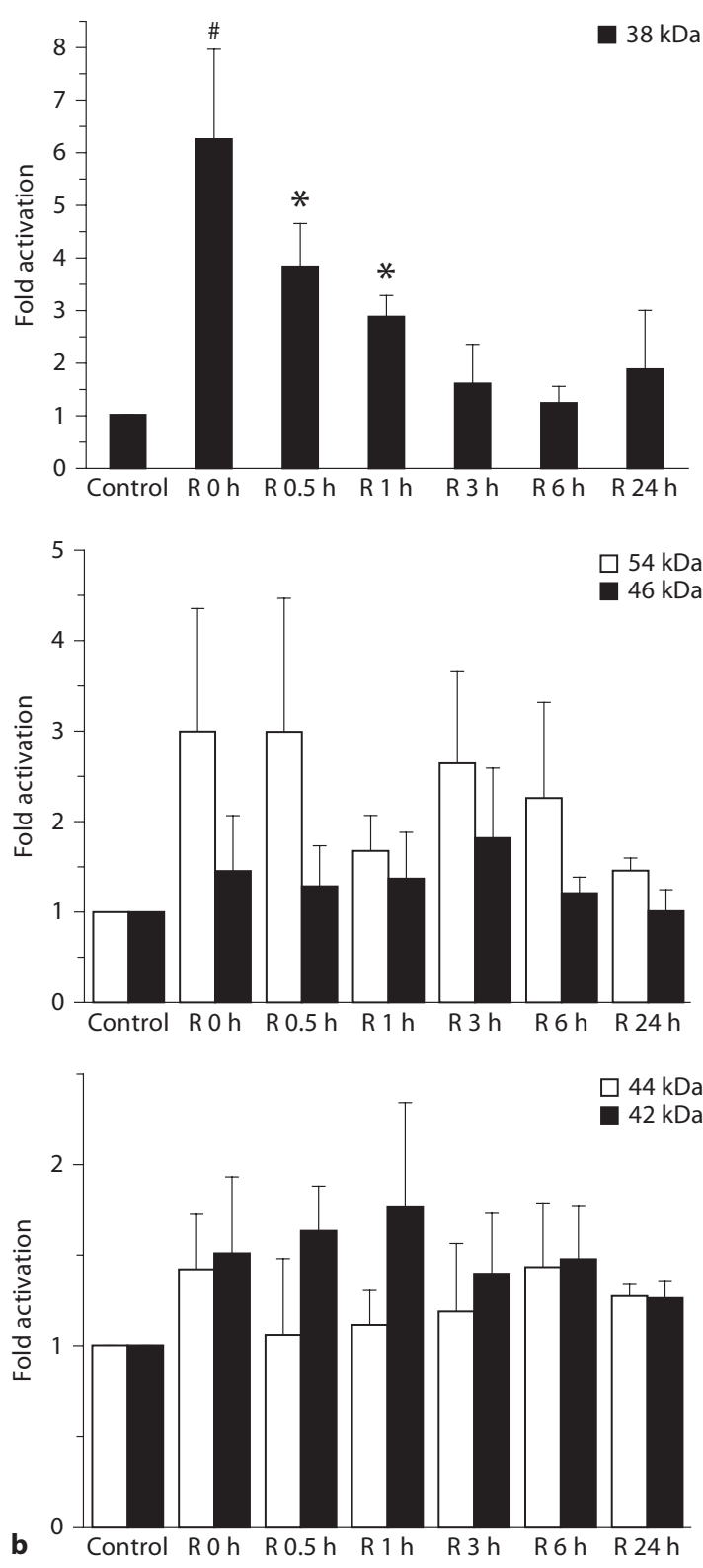

effect (fig. 4b). This result suggested that the production of $\mathrm{NO}$ might stimulate the activation of $\mathrm{p} 38$. Moreover, in the presence of L-NAME, the activation of $\mathrm{p} 38$ by H/R was blocked (fig. 5), which confirmed that $\mathrm{NO}$ was an upstream signaling molecule of p38.

Neurosignals 2009;17:162-168 

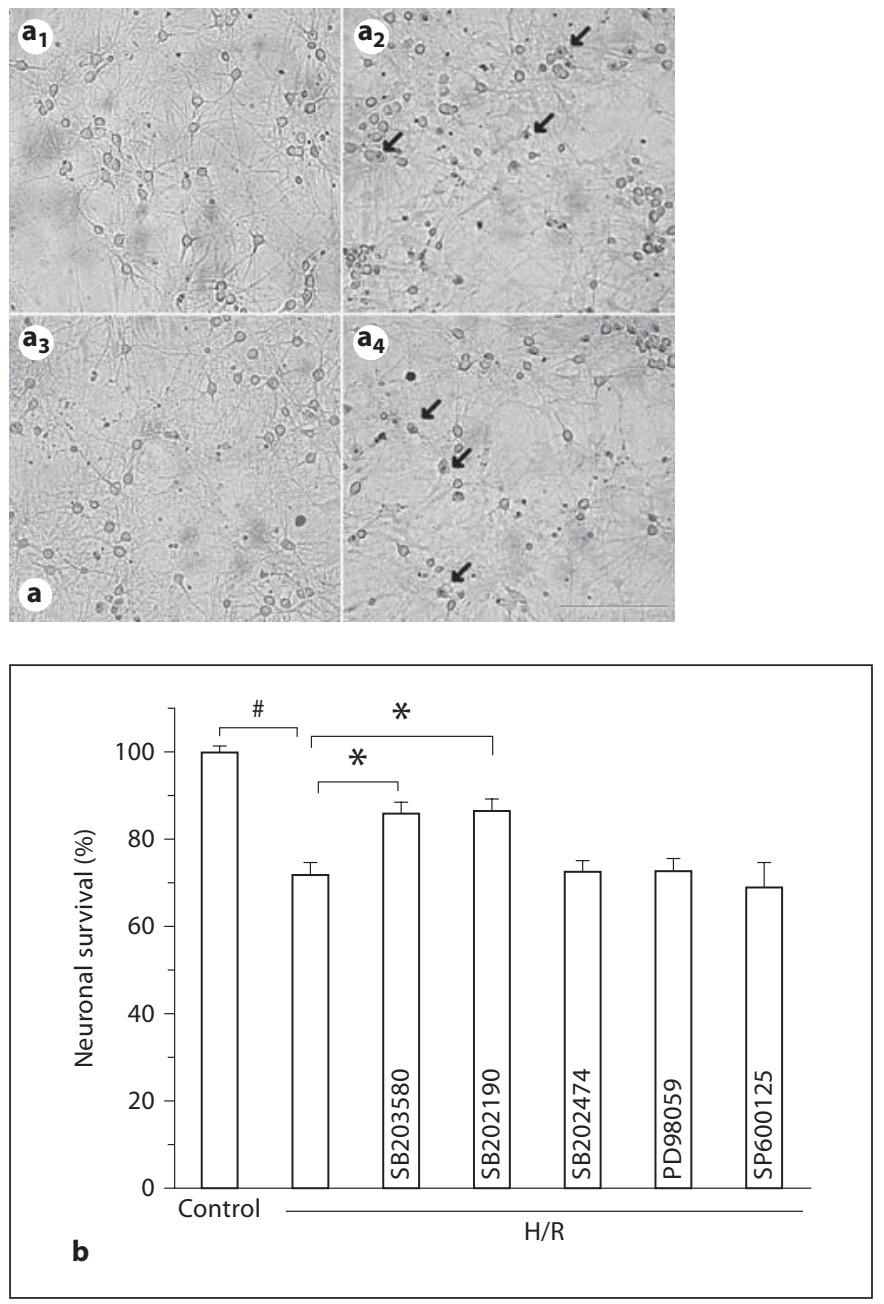

Fig. 3. Protection of H/R-induced neuronal death by p38 inhibitors. $10 \mu \mathrm{M}$ of inhibitors specific to different kinases were added to the culture medium before hypoxia. a Representative phasecontrast microphotographs of control $\left(\mathbf{a}_{\mathbf{1}}\right), \mathrm{H} / \mathrm{R}\left(\mathbf{a}_{\mathbf{2}}\right), \mathrm{H} / \mathrm{R}$ added with SB203580 $\left(\mathbf{a}_{\mathbf{3}}\right)$ and H/R added with SB202474 $\left(\mathbf{a}_{\mathbf{4}}\right)$. Photos were taken at $24 \mathrm{~h}$ after reoxygenation. Black arrows indicate the dying neurons. Bar $=200 \mu \mathrm{m}$. $\mathbf{b}$ Two p38 inhibitors, SB203580 or SB202190, rescued half of neuronal death, whereas its inactive analog SB202474, ERK inhibitor PD98059 or JNK inhibitor SP600125 afforded no protection. Neuronal survival was assessed using the MTT method and normalized with control as $100 \%$. ${ }^{\#} \mathrm{p}<0.001$ compared with control; ${ }^{*} \mathrm{p}<0.05$ compared with the $\mathrm{H} / \mathrm{R}$ group $(\mathrm{n}=12-16)$.

\section{Discussion}

\section{p38 Is a Candidate Mediator of H/R-Induced}

Hippocampal Neuronal Death

The major finding in the present study is that $\mathrm{NO}$ acts as an upstream signaling molecule of $\mathrm{p} 38$ to mediate the $\mathrm{H} / \mathrm{R}$-induced cell death in the cultured hippocampal
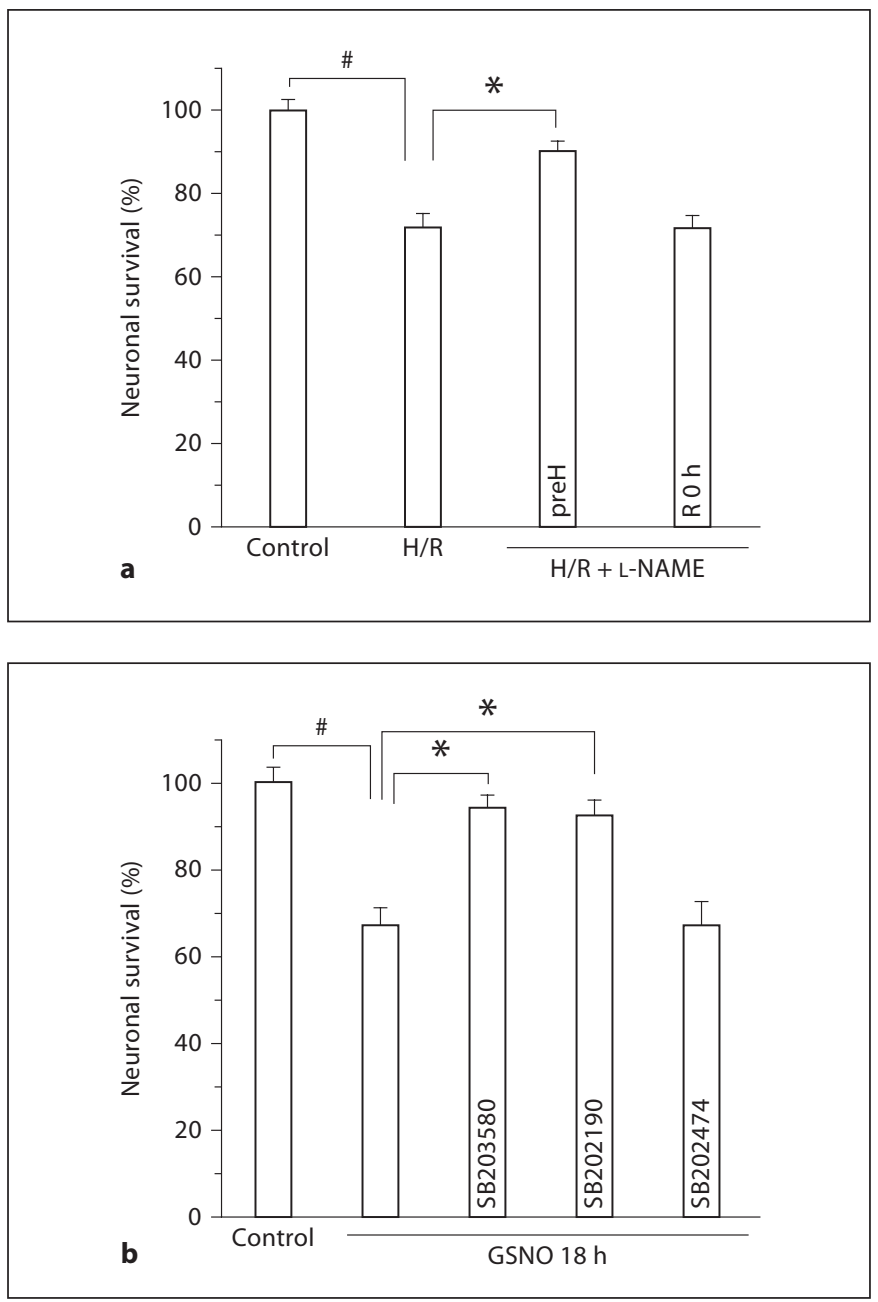

Fig. 4. Protection of $\mathrm{H} / \mathrm{R}$ - and $\mathrm{NO}$-induced neuronal death by NOS and p38 inhibitors, respectively. a Involvement of NO in $\mathrm{H} / \mathrm{R}$-induced neuronal death. Neuronal cultures were subjected to $\mathrm{H} / \mathrm{R}$. The NOS inhibitor L-NAME $(0.1 \mathrm{~mm})$ was applied either before hypoxia (preH) or at $0 \mathrm{~h}$ after reoxygenation (R0h). L-NAME reduced cell death when applied before hypoxia but not after reoxygenation. ${ }^{*} \mathrm{p}<0.001$ compared with control; ${ }^{*} \mathrm{p}<0.01 \mathrm{com}-$ pared with H/R group $(n=10-15)$. b Involvement of p38 in NOinduced neuronal death. Cultures were treated with $0.1 \mathrm{mM} \mathrm{GSNO}$ for $18 \mathrm{~h}$, and $10 \mu \mathrm{M}$ of MAPK inhibitors were added before GSNO treatment. p38 inhibitors prevented GSNO-induced cell death, while its inactive analog showed no effects. ${ }^{*} \mathrm{p}<0.001$ compared with control; ${ }^{*} \mathrm{p}<0.01$ compared with GSNO group $(\mathrm{n}=10)$.

neurons. The result that $\mathrm{p} 38$, JNK and ERK were activated after $H / R$ is consistent with previous reports in global or focal cerebral ischemia [13, 17]. The consequence of MAPK activation after insult is dependent on the immediate intracellular environment of the individual cell, the cell type, the number of kinase pathways activated at any given time, and the duration of kinase ac- 


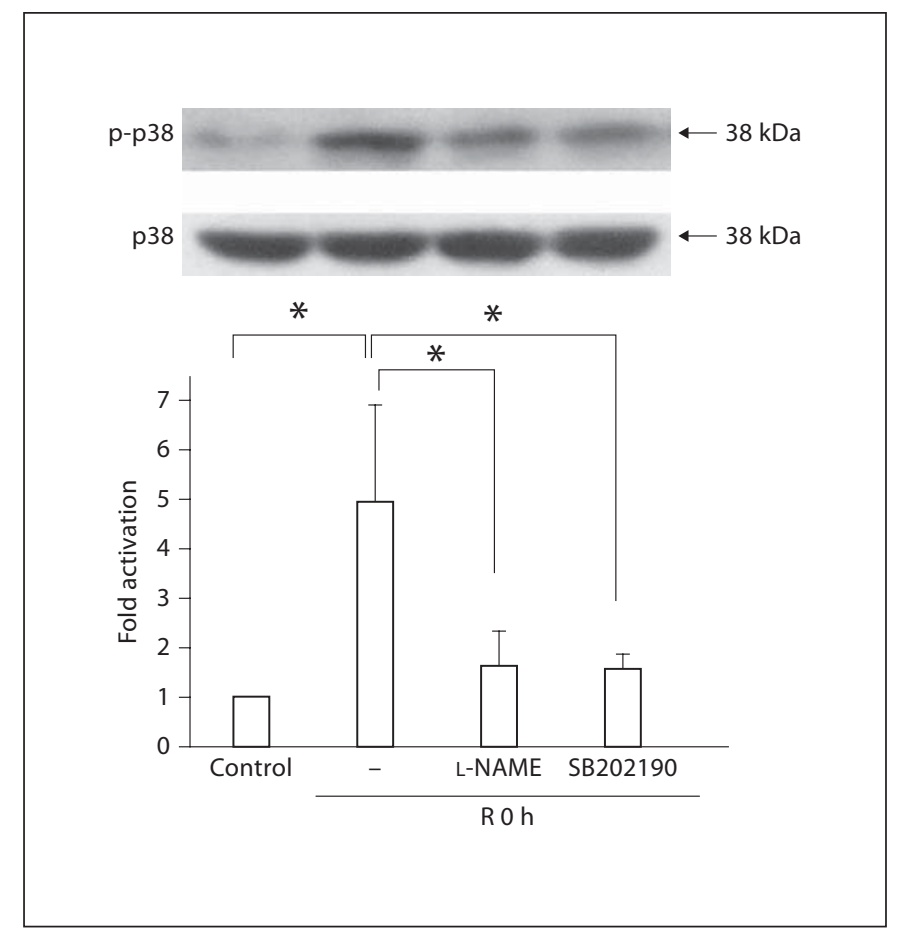

Fig. 5. Blockade of H/R-induced p38 activation by NOS inhibitor. L-NAME $(0.1 \mathrm{mM})$ and SB202190 $(10 \mu \mathrm{M})$ were added before hypoxia. SB202190 was used as a positive control. Activation of p38 at $0 \mathrm{~h}$ after reoxygenation was assessed by Western blot analysis. Results are from three experiments. ${ }^{*} \mathrm{p}<0.05$.

tivation [18]. Although the inhibition of p38 was demonstrated to provide protective effects on glutamate- or $\mathrm{NO}$ donor-induced neuronal death $[19,20]$, the role of p38 in neurons subjected to hypoxic insult was inconsistent [21, 22]. In cortical neurons, inhibition of $\mathrm{p} 38$ reduced hypoxic neuronal death [21]. However, in spinal cord neurons, no change in $\mathrm{p} 38$ kinase was detected after $\mathrm{H} / \mathrm{R}$, and inhibition of p38 did not provide protection [22]. Our data from hippocampal neurons suggest that $\mathrm{p} 38$ is a candidate mediator of neuronal death induced by H/R. The activation of p38 was transient in the neuronal cultures subjected to $H / R$, and the protective effects appeared only when the specific p38 inhibitors were applied before hypoxia, which indicates that p38 may be an early mediator in the starting up of neuronal death signaling induced by H/R. As shown in figure 2, although there is a tendency of greater activation fold of $\mathrm{p} 38$ at the later stage of reoxygenation, H/R-induced global suppression of protein translation due to activation of the unfolded protein response in the ER may lead to less phopho-p38 than in control conditions.

NO Mediates Hypoxic Neuronal Death Upstream of p38
It was reported that reduction in ERK or JNK activations by treatment of specific inhibitors offered neuroprotection against ischemia $[18,23]$. Although $H / R$ evoked mild activation of ERK and JNK in the present study, their inhibitors failed to protect the cells. This discrepancy may reflect the differences in severity of injury to neurons by the experimental ischemia model applied. In addition, changes that happened in multiple types of cells in ischemic animal make the explanation of results more complex than that in culture systems.

\section{NO Acts Upstream of 338 in H/R-Induced}

Hippocampal Neuronal Death

It has been shown that exogenous NO induces p38 activation in cultured neurons $[19,24]$. In a recent study, NO was found as an upstream regulator of p38 in glutamate-induced cerebellar granule neuronal death [20]. Consistent with this, our present results show that inhibition of NOS by L-NAME when applied before the induction of hypoxia blocks the activation of $\mathrm{p} 38$ and rescues the hypoxic neuronal death, indicating that endogenous NO production precedes $\mathrm{p} 38$ activation to mediate the $\mathrm{H} / \mathrm{R}$-induced neuronal injury. NO mediates the cellular effects mainly by two signaling mechanisms, cGMP pathway and S-nitrosylation. The cGMP pathway has been extensively documented for the effect on proteins by phosphorylation, whereas S-nitrosylation of proteins by chemical reactions with $\mathrm{NO}$ can modify protein functions [4]. Either increased cGMP levels or nitrosative stress have been reported to promote p38 activation in nonneuronal cells $[25,26]$. The mechanisms underlying NO modulation of p38 activity in ischemic/hypoxic neuronal death need further elucidation.

\section{Acknowledgements}

This work was supported by grants from NSFC (U0632007), National Basic Research Program of China (2006CB504100), PCSIRT (IRT0731), Key Project of Guangdong Province (06Z007, 2005A30801008) and Cheung Kong Scholars Programme to T.-M. Gao. 


\section{References}

1 Haddad GG, Jiang C: $\mathrm{O}_{2}$ deprivation in the central nervous system: on mechanisms of neuronal response differential sensitivity and injury. Prog Neurobiol 1993;40:277318.

-2 Mehta SL, Manhas N, Raghubir R: Molecular targets in cerebral ischemia for developing novel therapeutics. Brain Res Rev 2007;54: 34-66.

3 Szabo C: Physiological and pathophysiological roles of nitric oxide in the central nervous system. Brain Res Bull 1996;41:131-141.

-4 Lipton SA: Neuronal protection and destruction by NO. Cell Death Differ 1999;6:943951.

5 Tjong YW, Jian KH, Li M, Chen M, Gao TM, Fung ML: Elevated endogenous NO increases $\mathrm{Ca}^{2+}$ flux via L-type $\mathrm{Ca}^{2+}$ channels by $\mathrm{S}$ nitrosylation in rat hippocampal neurons during severe hypoxia and in vitro ischemia. Free Radic Biol Med 2007;42:52-63.

-6 Jian KH, Chen M, Cao X, Zhu XH, Fung ML, Gao TM: Nitric oxide modulation of voltagegated calcium current by S-nitrosylation and cGMP pathway in cultured rat hippocampal neurons. Biochem Biophys Res Commun 2007;359:481-485.

7 Willmot M, Gray L, Gibson C, Murphy S, Bath PM: A systematic review of nitric oxide donors and L-arginine in experimental stroke; effects on infarct size and cerebral blood flow. Nitric Oxide 2005;12:141-149.

$\checkmark 8$ Mungrue IN, Bredt DS: nNOS at a glance: implications for brain and brawn. J Cell Sci 2004;117:2627-2629.

$\checkmark 9$ Huang Z, Huang PL, Panahian N, Dalkara T, Fishman MC, Moskowitz MA: Effects of cerebral ischemia in mice deficient in neuronal nitric oxide synthase. Science 1994;265: 1883-1885.

10 Lipton P: Ischemic cell death in brain neurons. Physiol Rev 1999;79:1431-1568.

$\checkmark 11$ Cowan KJ, Storey KB: Mitogen-activated protein kinases: new signaling pathways functioning in cellular responses to environmental stress. J Exp Biol 2003;206:11071115.
12 Xia Z, Dickens M, Raingeaud J, Davis RJ, Greenberg ME: Opposing effects of ERK and JNK-p38 MAP kinases on apoptosis. Science 1995;270:1326-1331.

13 Ozawa H, Shioda S, Dohi K, Matsumoto H, Mizushima H, Zhou CJ, Funahashi H, Nakai Y, Nakajo S, Matsumoto K: Delayed neuronal cell death in the rat hippocampus is mediated by the mitogen-activated protein kinase signal transduction pathway. Neurosci Lett 1999;262:57-60.

14 Sugino T, Nozaki K, Takagi Y, Hattori I, Hashimoto N, Moriguchi T, Nishida E: Activation of mitogen-activated protein kinases after transient forebrain ischemia in gerbil hippocampus. J Neurosci 2000;20:45064514.

$>15$ Li XM, Yang JM, Hu DH, Hou FQ, Zhao M, Zhu XH, Wang Y, Li JG, Hu P, Chen L, Qin LN, Gao TM: Contribution of down-regulation of L-type calcium currents to delayed neuronal death in rat hippocampus after global cerebral ischemia and reperfusion. J Neurosci 2007;27:5249-5259.

16 Bossenmeyer C, Chihab R, Muller S, Schroeder H, Daval JL: Hypoxia/reoxygenation induces apoptosis through biphasic induction of protein synthesis in central neurons. Brain Res 1998;787:107-116.

$>17$ Ferrer I, Friguls B, Dalfo E, Planas AM: Early modification in the expression of mitogen-activated protein kinase (MAPK/ERK), stress-activated kinases SAPK/JNK and p38, and their phosphorylated substrates following focal cerebral ischemia. Acta Neuropathol (Berl) 2003;105:425-437.

18 Irving EA, Bamford M: Role of mitogen- and stress-activated kinases in ischemic injury. J Cereb Blood Flow Metab 2002;22:631-647.
19 Bossy-Wetzel E, Talantova MV, Lee WD, Scholzke MN, Harrop A, Mathews E, Gotz T, Han J, Ellisman MH, Perkins GA, Lipton SA: Crosstalk between nitric oxide and zinc pathways to neuronal cell death involving mitochondrial dysfunction and p38-activated $\mathrm{K}^{+}$channels. Neuron 2004;41:351-365.

20 Cao J, Viholainen JI, Dart C, Warwick HK, Leyland ML, Courtney MJ: The PSD95nNOS interface: a target for inhibition of excitotoxic p38 stress-activated protein kinase activation and cell death. J Cell Biol 2005; 168:117-126.

21 Zhu Y, Mao XO, Sun Y, Xia Z, Greenberg DA: p38 mitogen-activated protein kinase mediates hypoxic regulation of $\mathrm{Mdm} 2$ and $\mathrm{p} 53$ in neurons. J Biol Chem 2002;277:2290922914.

22 Vartiainen N, Goldsteins G, Keksa-Goldsteine V, Chan PH, Koistinaho J: Aspirin inhibits p44/42 mitogen-activated protein kinase and is protective against hypoxia/reoxygenation neuronal damage. Stroke 2003; 34:752-757

23 Okuno S, Saito A, Hayashi T, Chan PH: The c-Jun N-terminal protein kinase signaling pathway mediates Bax activation and subsequent neuronal apoptosis through interaction with Bim after transient focal cerebral ischemia. J Neurosci 2004;24:7879-7887.

24 Ghatan S, Larner S, Kinoshita Y, Hetman M, Patel L, Xia Z, Youle RJ, Morrison RS: p38 MAP kinase mediates Bax translocation in nitric oxide-induced apoptosis in neurons. J Cell Biol 2000;150:335-347.

$>25$ Schieke SM, Briviba K, Klotz L, Sies H: Activation pattern of mitogen-activated protein kinases elicited by peroxynitrite: attenuation by selenite supplementation. FEBS Lett 1999; 448:301-303.

26 Pyriochou A, Beis D, Koika V, Potytarchou C, Papadimitriou E, Zhou Z, Papapetropoulos A: Soluble guanylyl cyclase activation promotes angiogenesis. J Pharmacol Exp Ther 2006;319:663-671. 